\title{
Cost of Treatment of Valvular Heart Disease at a Tertiary Hospital in North India: Policy Implications
}

\author{
Shankar Prinja ${ }^{1}\left[\right.$ - Yashpaul Sharma ${ }^{2} \cdot$ Jyoti Dixit $^{1} \cdot$ Shyam Kumar Singh Thingnam ${ }^{3} \cdot$ Rajesh Kumar $^{1}$
}

Published online: 19 February 2019

(c) The Author(s) 2019

\begin{abstract}
Background Lack of data on the cost of cardiac care is an impediment to evidence-based planning, especially for determining provider payment rates under publically financed health insurance schemes.

Objective This study estimates the unit costs of outpatient consultation, hospitalization, intensive care, selected surgical procedures and diagnostics for providing cardiac care for valvular heart disease at a tertiary hospital in India.

Methods We undertook an economic costing of cardiac care using both patient and health system perspectives. For the health system costs, a bottom-up costing methodology was used. Data on all resources (capital and recurrent) utilized for the delivery of cardiac care services for valvular heart disease for 1 year were collected. Data on out-of-pocket expenditures was collected from 100 cardiac patients who underwent valve replacement and balloon valvotomy procedures. All estimated costs represent the year 2016-2017.

Results The health system cost of an outpatient cardiac consultation was estimated as 182.4 Indian rupees (INR) (US\$2.8) and INR334.8 (US\$5.2) in the cardiology, and cardio-thoracic and vascular surgery (CTVS) departments, respectively. The cost of hospitalization per bed-day in cardiology, CTVS and the intensive care unit (ICU) was INR1040 (US\$16), INR3853 (US\$60) and INR12,635 (US\$197), respectively. The median out-of-pocket expenditure for valve replacement surgery using mechanical and bio-prosthetic valves was estimated to be INR107,800 (US\$1684) and INR154,000 (US\$2406), respectively, and for balloon valvotomy was estimated to be INR14,456 (US\$367). Overall package cost per mechanical and bio-prosthetic single valve replacement surgery and balloon valvotomy procedure was estimated as INR127,919 (US\$1999), INR148,919 (US\$2372) and INR14,456 (US\$226), respectively.

Conclusion Our findings are useful for planning expansion of public sector cardiac care services, developing package rates for publically financed insurance schemes in India and for undertaking research on cost effectiveness of various models of cardiac care.
\end{abstract}

\section{Key Points for Decision Makers}

The treatment of valvular heart disease imposes high out-of-pocket expenditure for households.

Electronic supplementary material The online version of this article (https://doi.org/10.1007/s41669-019-0123-6) contains supplementary material, which is available to authorized users.

Shankar Prinja

shankarprinja@gmail.com

1 School of Public Health, Postgraduate Institute of Medical Education and Research, Chandigarh, India

2 Department of Cardiology, Postgraduate Institute of Medical Education and Research, Chandigarh, India

3 Department of Cardiothoracic and Vascular Surgery (CTVS), Postgraduate Institute of Medical Education and Research, Chandigarh, India
Our study findings on the overall cost of treatment of valvular heart disease support the provider payment rates set under Ayushman-Bharat Pradhan Mantri Jan Arogya Yojana (AB-PMJAY).

Our findings could be used for setting reimbursement decisions for cardiac surgeries in various publicly financed insurance schemes as well as assessing cost effectiveness of related interventions. 


\section{Introduction}

Cardiovascular disease (CVD) is a leading cause of mortality globally $[1,2]$. It is responsible for $10 \%$ and $18 \%$ of the disability-adjusted life-years (DALYs) lost in low-middle and high-income countries, respectively [3]. The estimated global cost of CVDs was US $\$ 863$ billion in 2010 , which is estimated to rise to US $\$ 1044$ billion by 2030 [4]. A reduction in CVD mortality by $10 \%$ would result in a US $\$ 377$ billion savings from 2011 to 2025 [5, 6].

Among CVDs, heart valve disorders have a profound impact on the use and costs of health care. This impact is greater for heart valve diseases than for other cardiac pathologies like coronary artery disease, despite the higher prevalence of coronary artery disease [7]. This is probably because of the rising prevalence of heart valve diseases with age [8]. Thus, due to an ageing population, the number of patients with heart valve diseases requiring valve replacement surgery is expected to rise, reaching more than 800,000 annual procedures by 2050 [9]. As a result, healthcare expenditure and the societal burden of heart valve disorders will increase.

As India progresses towards Universal Health Coverage (UHC), it grapples with the dual challenges of how to provide universal access to essential health services and ensure financial sustainability. Recognizing the tension between these two goals, various initiatives have been taken up by the government of India to make cardiac care affordable and accessible to all. Rashtriya Bal Swasthya Karyakram (RBSK), a programme for screening and treatment of newborns and children for congenital CVDs, is one such programme [10]. Provision of tertiary care is being strengthened under Pradhan Mantri Swasthya Suraksha Yojana (PMSSY) [11]. The National Programme for Prevention and Control of Cancer, Diabetes, Cardiovascular Diseases and Stroke (NPCDCS) aims to establish non-communicable disease (NCD) clinics at all levels, set up intensive cardiac care at district hospitals and advanced cardiac care centres at tertiary-level hospitals [12]. The Government of India and the State governments have implemented several tax-funded health insurance schemes. Provision of cardiac care is an integral component of the benefit packages of all these schemes [10, 13]. Planning and management of these programme initiatives require evidence on cost of cardiac care services. Hospital costs of CVD care are also important for establishing provider payment rates in publically financed health insurance schemes.

The government has recently launched the AyushmanBharat Pradhan Mantri Jan Arogya Yojana (AB-PMJAY), which will be a completely tax-funded scheme to provide secondary and tertiary care for up to 500,000 Indian rupees (INR) per year per household. Several recent media reports have raised the issue of lack of scientific evidence in determination of package rates under this scheme [14]. Therefore, robust costing studies need to be undertaken for designing appropriate package rates for the successful implementation of the scheme. Evidence on costs is also necessary to assess the cost effectiveness of various models of care.

Despite an emphasis on strengthening the public health delivery system for provision of cardiac care, there is no study that focusses on the health system cost of cardiac care in particular. Several studies in India have reported the cost of cardiac care from a patient's perspective [15-18]. However, there is a lack of robust evidence on its economic implications from the health system's or Government's perspective. In our review, we found only one study that estimated the health system cost of providing various tertiary care services in general with slight focus on cardiovascular services, which has cited several limitations such as lack of access to price data for some equipment, non-inclusion of donated items, non-representative sample of study hospitals, and non-inclusion of patient's costs $[19,20]$. In order to address this gap, we estimated the full cost of specific cardiac care services for valvular heart disease at a tertiary care hospital from both health system and patient perspectives. Specifically, we report the unit cost of an outpatient consultation, per bed-day cost of hospitalization, per bed-day cost of intensive care, valve replacement surgery, balloon valvotomy and diagnostic services such as echocardiography (ECHO), electrocardiography (ECG), Treadmill Test (TMT) and Holter tests for providing cardiac care through a tertiary-level hospital.

\section{Methodology}

\subsection{Study Setting}

The study was undertaken at the Postgraduate Institute of Medical Education and Research (PGIMER), Chandigarh, which is a large tertiary care hospital in the public sector in North India. With a total of 356 consultants and nearly 2000 resident doctors, the hospital has an annual inpatient and outpatient attendance of 78,568 and 2,061,911 patients, respectively [21].

Cost analysis was undertaken in the Advanced Cardiac Centre (ACC), which is a state-of-the-art 210-bed cardiac care facility. The ACC has facilities for outpatient consultation and hospitalization in cardiology and Cardiothoracic and Vascular Surgery (CTVS) departments, respectively. It has various diagnostic facilities including Holter Monitoring, TMT, radiological tests, laboratory and cardiac-specific diagnostic tests (coronary angiography, endo-myocardial 
biopsy, etc.). Nearly 1500 cardiac surgeries were performed during 2016-2017.

\subsection{Study Design}

Costing was done from both health system and patient perspectives. Health system cost was measured using bottom-up costing methods [22, 23]. Firstly, cost centres were classified as primary and secondary cost centres. Primary cost centres included direct and indirect care centres. In the cardiology department, there were three direct primary-care centres: outpatient department (OPD), inpatient department (IPD) and catheterization laboratory. Cost centres in the CTVS department included OPD, IPD and operation theatre (OT). Indirect care centres include radiology department, which has a diagnostic centre at ACC for performing tests like ECG, ECHO, TMT and Holter Tests. Secondary cost centres include laundry, dietetics, water, electricity and maintenance.

\subsection{Data Collection}

\subsubsection{Health System Costs}

Data on resources consumed for provision of cardiac care was collected from April 2016 to March 2017. A standardized tool used for economic costing studies of health facilities in India was used to collect data [24-27]. Information regarding space was collected from the Hospital Engineering Department. Data on number of OPD consultations, IPD admissions and IPD bed days was obtained from medical records at Central Registration Department (CRD). The number of valve replacement surgeries and balloon valvotomies performed during the last year was collected from the OT and catheterization lab register, respectively. Year of purchase and prices of medical and non-medical equipment were obtained from the procurement branch of the study hospital. Quantity of drugs, consumables and nonconsumables used were collected from stock registers of respective departments, while average life of capital equipment was obtained by consulting the technician in charge of the unit. Salary slips of staff employed at various cost centres were obtained from the accounts department to collect data on salaries and other allowances. Ten percent of the staff from each category were randomly interviewed using a pretested questionnaire to assess time allocation for various activities. Time allocation reported by participants was further validated using actual observation on randomly selected participants and review of duty rosters for a period of 4 months. Sources of data along with an overview of methods and criteria used for apportioning joint costs are described in Table 1.

\subsubsection{Out-of-Pocket Expenditures}

A total of 100 patients who underwent valve replacement surgery and balloon valvotomy were interviewed telephonically using a semi-structured interview schedule (see Annexure-1 in electronic supplementary material) in order to assess the data on out-of-pocket (OOP) expenditure [28]. This methodology of collecting information on OOP expenditure using telephonic interviews has been reported to be valid [29].

\subsection{Data Analysis}

\subsubsection{Health System Costs}

For building and space costs, rental price was multiplied by the floor area to estimate the opportunity cost of the building being used. Annualized cost of other capital resources was estimated considering the average life of an item at a discount rate of $3 \%$ [30, 31]. Costs were converted to US dollars (USD) using a conversion rate of 1 USD equivalent to INR64 [32]. Unit costs of cardiac care were estimated per OPD consultation, per inpatient bed-day, per valve replacement, per balloon valvotomy and per selected diagnostic test done.

Apportioning statistics: For resources used in a specific cost centre only, the entire cost was taken. Appropriate apportioning statistics were used to allocate shared or joint resources; that is, resources that were being used to provide more than one type of service, or in multiple cost centres, or in multiple types of patients. Firstly, the shared human resource cost was apportioned to outpatient care, surgical procedure, intensive care unit (ICU) care, non-ICU inpatient care and other general teaching and administrative work. The human resource (HR) costs were apportioned on the basis of time spent in each cost centre. For the cost of valve replacement, the HR costs were apportioned on the basis of time devoted to each type of valve replacement surgery by human resources directly involved in the surgery (anaesthetist, surgeon, resident doctors, perfusionist, OT assistant, nursing and support staff). Similarly, for the cost of balloon valvotomy, apportioning of HR costs was done on the basis of time devoted to balloon valvotomy procedure by consultants, resident doctors, senior and junior technicians. However, the costs of HR who were indirectly involved (other nursing staff, health and sanitary attendants) were apportioned on the basis of proportion of different surgeries conducted in the last year. The cost of shared buildings/ space (i.e. waiting area and reception area) were apportioned among various cost centres on the basis of proportion of patients. The shared capital cost for valve replacement and balloon valvotomy specifically was apportioned on the basis of time period for which the space of a given cost centre was 


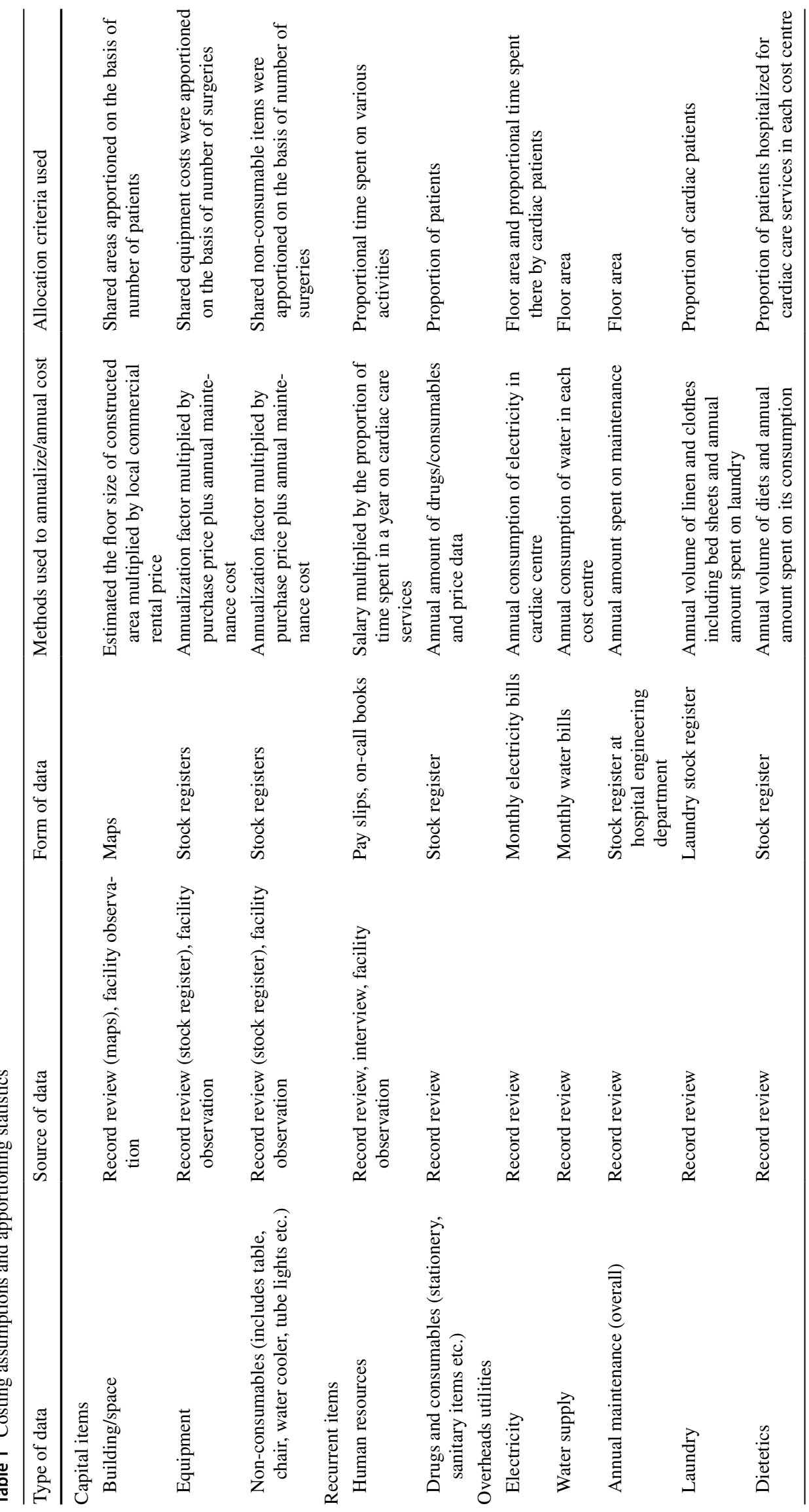


used. The cost of overhead utilities (electricity, water supply, maintenance, including installation of UPS systems and generators) were apportioned on the basis of floor area [33, 34].

\subsubsection{Out-of-Pocket Expenditures}

Mean OOP expenditure for valve replacement surgery and balloon valvotomy was computed along with its standard error. The proportional contribution of different constituents such as medicines, surgical procedure, laboratory/diagnostic tests, user fees/hospital charges including bed charges, boarding/lodging of food and travel was also calculated.

\subsection{Ethical Consideration}

The study was approved by the Institute Ethics Committee of the Postgraduate Institute of Medical Education and Research, Chandigarh, India. Written informed consent was obtained from participants (hospital staff) prior to the interview for time allocation. Verbal consent was taken from patients who were interviewed telephonically for assessing OOP expenditures.

\section{Results}

\subsection{Profile of Study Hospital}

The number of outpatient visits in the department of cardiology and CTVS in 2016-2017 was 141,956 and 29,789, respectively. The annual number of cardiac care unit (CCU) and non-CCU hospitalizations in the cardiology department were 9168 and 2628, respectively, during 2016. The annual number of patients admitted to a CTVS general ward and private ward were 1069 and 84, respectively. A total of 1404 cardiac surgeries were performed, which included 202 valve replacements (single valve replacements, 124; double valve replacements, 54 and triple valve replacements, 24). A total of 9598 procedures were performed in the catheterization laboratory in the year 2017, which included 129 balloon valvotomies.

\subsection{Annual Health System Costs}

The annual cost incurred on outpatient consultation in the cardiology and CTVS departments was found to be INR25 million (US\$390,625) and INR9 million (US\$140,625), respectively. Annual cost for provision of in-patient cardiac care was estimated to be INR134 million (US\$2,093,750) and INR66 million (US $\$ 1,031,250$ ) in cardiology and CTVS, respectively. Input-wise distribution of cost incurred for providing cardiac care services was also calculated as mentioned in Fig. 1.

\subsection{Unit Health System Costs}

The hospital incurred INR182.4 (US\$2.8) and INR334.8 (US\$5.2) per outpatient visit in cardiology and CTVS departments, respectively. The unit costs per ECHO, ECG, TMT and Holter were INR358 (US\$5.6), INR18 (US\$0.3), INR963 (US\$15) and INR1892 (US\$29.5) respectively. The cost per bed-day of hospitalization in cardiology and CTVS wards was INR1040 (US\$16) and INR3853 (US\$60), respectively. The cost of intensive cardiac care was INR12,635 (US\$197) per bed-day hospitalization (Table 2).

The overall unit health system cost per single valve, double valve and triple valve surgery was found to be INR72,919 (US\$1139.3), INR76,330 (US\$1192.6) and INR89,125 (US\$1392.5), respectively, considering an average stay of 1.5 days based on actual data collection from the ICU and cardio-thoracic and vascular surgery ward during the study period and assuming one outpatient consultation in the CTVS department for the same. Per-unit health system cost for balloon valvotomy was estimated as INR8374 (US\$130.8) considering an average stay of 1.5 days in the cardiology ward based on expert opinion and assuming one outpatient consultation in the cardiology department for the same (Table 3).

\subsection{Out-of-Pocket Expenditures}

The socio-demographic features of patients with valvular heart disease were assessed and it was found that the majority of patients fall in the age group of 15-30 years (41\%), followed by $30-45$ years (31\%) and $45-60$ years (21\%). It clearly states that this disease continues to affect patients throughout their life and affects the most productive years of life. This disease is found to be more prevalent among females. It is found to be more prevalent among those who have not attained higher education, with the majority of patients having senior secondary (23\%), followed by matric (22\%) and no education at all (14\%). The majority of the valvular heart disease patients were found to be married (68\%) and unpaid family workers (59\%), as shown in Table 4.

The median OOP expenditure for valve replacement surgery using mechanical and bio-prosthetic valves was estimated to be INR107,800 (US\$1684) and 154,000 (US\$2406), respectively (Table 5). The majority of OOP expenditure was incurred on the cost of the valves (ranging from 50 to $57 \%$ for mechanical and bio-prosthetic valves, respectively) followed by medicines (26\%), diagnostics (4-5\%), hospital charges (3-5\%), travelling (3-9\%) etc. 

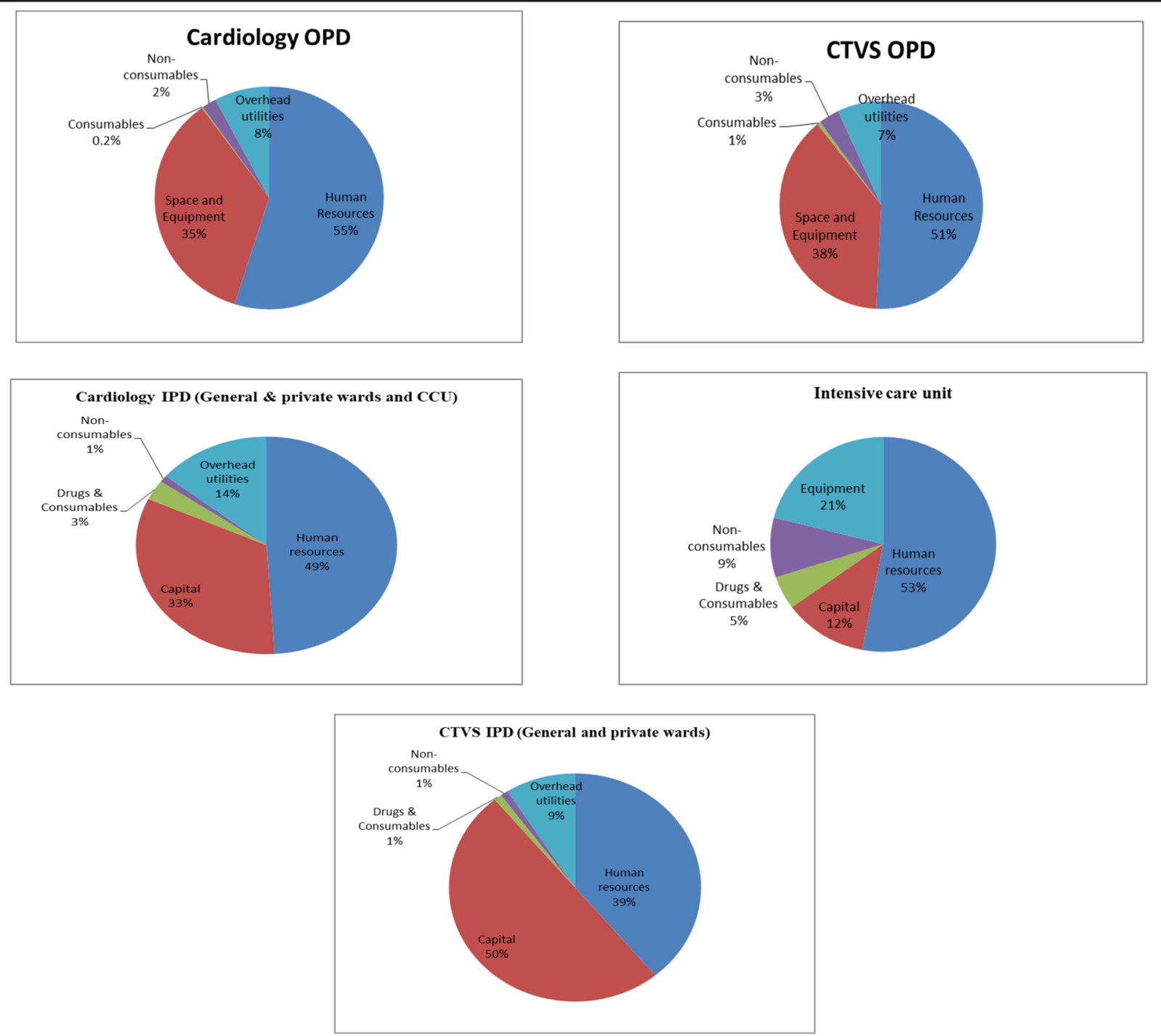

*OPD-Outpatient department, IPD-Inpatient department, CCU-Cardiac Care Unit, CTVS-

Cardiovascular and thoracic surgery.

Fig. 1 Input-wise distribution of cost incurred for providing cardiac care services

The median OOP for balloon valvotomy was estimated to be INR23,481.9 (US\$7041.7). The distribution of costs on various services is listed in Table 5.

\subsection{Package Cost of Valve Replacement Surgery and Balloon Valvotomy}

The overall package cost (total health system cost and cost of valve) of a single valve replacement surgery for mechanical and bio-prosthetic valves was estimated as INR127,919 (US\$1999) and INR 148,919 (US\$2372), respectively. The package cost for a double valve replacement was estimated as INR186,330 (US\$2911) for mechanical valves and INR228,330 (US\$3568) for bioprosthetic valves. The triple valve replacement surgery package cost for mechanical and bio-prosthetic valves was estimated as INR254,125 (US\$3971) and INR317,125 (US\$4955), respectively. The overall package cost of 
Table 2 Unit health system cost of cardiac care services in a tertiary care hospital, 2016-2017

\begin{tabular}{lcccc}
\hline Cost centres & \multicolumn{1}{l}{$\begin{array}{l}\text { Total cost } \\
\text { INR (US\$) }\end{array}$} & $\begin{array}{c}\text { Output (no. } \\
\text { of patients) }\end{array}$ & Unit & \multicolumn{1}{c}{$\begin{array}{l}\text { Unit cost } \\
\text { INR (US\$) }\end{array}$} \\
\hline Intensive care unit & $55,642,558(869,415)$ & 2936 & Bed days & $12,635(197)$ \\
Cardiology general and private wards & $134,926,873(2,108,232)$ & 11,796 & Bed days & $1040(16)$ \\
CTVS general and private wards & $66,641,429(1,041,272)$ & 1153 & Bed days & $3853(60)$ \\
Outpatient department (cardiology) & $25,899,007(404,672)$ & 141,956 & Visits & $182.4(2.8)$ \\
Outpatient department (CTVS) & $9,974,384(155,850)$ & 29,789 & Visits & $334.8(5.2)$ \\
Radiology department & $21,097,709(329,652)$ & 202,304 & Cases & $104(1.6)$ \\
ECG & $3,143,005(49,109)$ & 170,279 & Cases & $18(0.3)$ \\
ECHO & $9,193,724(43,652)$ & 25,662 & Cases & $358(5.6)$ \\
TMT & $4,952,522(77,383)$ & 5140 & Cases & $963(15)$ \\
Holter & $2,314,605(36,166)$ & 1223 & Cases & $1892(29.5)$ \\
\hline
\end{tabular}

CTVS Cardiothoracic and Vascular Surgery, ECG electrocardiography, ECHO echocardiography, INR Indian rupees, TMT treadmill test

Table 3 Total health system cost of valve replacement surgery and balloon valvotomy in India

\begin{tabular}{|c|c|c|c|c|c|c|}
\hline \multirow[t]{2}{*}{ Cost centre } & \multirow{2}{*}{$\begin{array}{l}\text { Quantity of } \\
\text { services }\end{array}$} & \multirow[t]{2}{*}{ Unit } & \multicolumn{4}{|c|}{ Total health system cost in INR (US\$) } \\
\hline & & & $\begin{array}{l}\text { Single valve } \\
\text { replacement } \\
\text { surgery }\end{array}$ & $\begin{array}{l}\text { Double valve } \\
\text { replacement surgery }\end{array}$ & $\begin{array}{l}\text { Triple valve } \\
\text { replacement } \\
\text { surgery }\end{array}$ & Balloon valvotomy \\
\hline Outpatient department & 1 & Visits & $334.8(5.2)$ & $334.8(5.2)$ & $334.8(5.2)$ & $182.4(2.8)$ \\
\hline Intensive care unit & 1.5 & Bed days & $18,952.5(296)$ & $18,952.5(296)$ & $18,952.5(296)$ & \\
\hline Inpatient department & 1.5 & Bed days & $5779.5(90)$ & $5779.5(90)$ & $5779.5(90)$ & $1560(24.3)$ \\
\hline $\begin{array}{l}\text { Operation theatre/cath- } \\
\text { eterization lab }\end{array}$ & 1 & Procedure & $47,853(748)$ & $51,264(801)$ & $64,059(1001)$ & $6632(104)$ \\
\hline Total health system cost & & & $72,919(1139.3)$ & $76,330(1192.6)$ & $89,125(1392.5)$ & $8374(130.8)$ \\
\hline
\end{tabular}

$I N R$ Indian rupees

balloon valvotomy, which includes health system cost and OOP expenditure (exclusive of user fees), was estimated as INR14,456 (US\$226).

\section{Discussion}

\subsection{Overview of Present Study Findings}

The increased demand for cardiac care along with its high cost imposes a significant fiscal pressure on the government as well as financial hardship for households. In India, $>70 \%$ of the overall health expenditure is paid OOP, which puts a huge financial burden on citizens [35, 36]. Considering this, the Government of India pooled a large amount of money towards cardiac care through various initiatives [10-12]. However, there are no empirically derived estimates of the cost for providing cardiac care in India. Therefore, the present study was undertaken to estimate the cost of various cardiac care services for treatment of valvular heart disorders. The unit cost estimates per outpatient consultation and per bed-day of hospitalization found in our study are in concordance with the findings of other studies [20, 26, 27]. Unit cost per outpatient consultation at a tertiary care hospital reported by Chatterjee et al. (2013) was found to be INR242, which is close to findings from our study (INR182 and INR334 for outpatient consultations at cardiology and CTVS departments, respectively) [20]. However, the cost per bed-day of hospitalization in the general medicine ward (INR614) found by Chatterjee and Laxminarayan is slightly lower compared with our study findings (INR1040) [19]. This could be due to the specific focus on cardiac care services in our study, which require more specialized and resource intensive care. Per-bed-day cost of intensive cardiac care (INR12,635) found in our study is also consistent with per-bed-day cost of INR12,905 for ICU care in a tertiary care hospital reported earlier [26].

Human resources were found to be the major component of cost of cardiac care, followed by capital resources as shown in Fig. 1, which is also consistent with the findings of the working group on tertiary care institutions in 
Table 4 General characteristics of patients with valvular heart diseases during 2016-17

\begin{tabular}{|c|c|c|}
\hline Characteristic & Category & $\begin{array}{l}\text { Number } \\
(N=100)\end{array}$ \\
\hline Mean age (in years) & 36 years & 100 \\
\hline \multirow[t]{2}{*}{ Gender } & Male & 42 \\
\hline & Female & 58 \\
\hline \multirow[t]{5}{*}{ Religion } & Hindu & 59 \\
\hline & Muslim & 2 \\
\hline & Sikh & 38 \\
\hline & Christian & 0 \\
\hline & Other & 1 \\
\hline \multirow[t]{4}{*}{ Caste } & $\mathrm{SC}$ & 28 \\
\hline & ST & 1 \\
\hline & $\mathrm{OBC}$ & 20 \\
\hline & General & 51 \\
\hline \multirow[t]{2}{*}{ Locality } & Urban & 49 \\
\hline & Rural & 51 \\
\hline \multirow[t]{6}{*}{ Educational status } & Illiterate & 14 \\
\hline & Primary & 12 \\
\hline & Middle & 11 \\
\hline & Matric & 22 \\
\hline & Senior secondary & 23 \\
\hline & Graduation and above & 18 \\
\hline \multirow[t]{3}{*}{ Marital status } & Unmarried & 30 \\
\hline & Married & 68 \\
\hline & Widow/widower & 2 \\
\hline \multirow[t]{5}{*}{ Wealth quintiles } & Poorest & 19.9 \\
\hline & Poor & 19.9 \\
\hline & Moderate & 19.9 \\
\hline & Rich & 19.9 \\
\hline & Richest & 20.2 \\
\hline
\end{tabular}

OBC Other Backward Caste, SC Scheduled Castes, ST Scheduled Tribes

India, which showed that in most states, salaries and wages account for as much as $70 \%$ of the total health budget [37]. Our study findings are also comparable to another study by Prinja et al., where cost of delivering various healthcare services were estimated and it was found that cost of human resource alone accounted for $52.6 \%$ and $58.9 \%$ of total costs at PHC and CHC, respectively [27]. Several other national and international studies on hospital costings also found that human resources constitute the majority of a hospital's total operating cost $[20,26,38]$.

\subsection{Policy Implication}

Our results have significant policy implications. Policy discourse in India is gradually building towards universal provision of healthcare services [39]. Most policy documents recommend greater reliance on a tax-funded system of financing for provision of healthcare. Models of both publicly delivered healthcare services and purchasing of health care services through publicly financed health insurance schemes are evident in this context [40].

The emergence of the recently launched AyushmanBharat Pradhan Mantri Jan Arogya Yojana (AB-PMJAY) is a welcome development as it brings health to the forefront of the political arena and mainstream public discourse. The success of this scheme is largely dependent on the fact that the services prioritized under the scheme are evidencebased, well governed, transparent and inclusive [41]. Our study can play an important role in generating scientific evidence for determining package rates for cardiac care services to ensure maximum value of expenditure under this programme.

Several initiatives have been taken up by the central government (through Rashtriya Swasthya Bima Yojana [10], and state-sponsored schemes such as Arogyasree Health Insurance Scheme, Telangana [42], Mahatama Jyotiba Phule Jan Arogya Yojana in Maharashtra [43] and Chief Minister's Comprehensive Health Scheme in Tamil Nadu [44], for example, in order to meet the need for affordable tertiary care for poor people. More recently, the AB-PMJAY envisages a much higher benefit package. The provider payment rates (package rates) under the AB-PMJAY scheme for single valve replacement surgery (mechanical: INR120,000 and bio-prosthetic: INR125,000) and double valve replacement surgery (mechanical: INR 150,000 and bio-prosthetic: INR 155,000) are close to the actual estimates found in our study, and are likely to be justifiable given that Government will become the largest monopsonistic purchaser of health care, with the potential to lower costs. Moreover, the Government has reserved a nearly $10 \%$ increase in payment rates to hospitals that ensure quality standards as per guidelines. Hence, the rates under the Government's AB-PMJAY scheme appear justified.

Our study findings show that cost of valves is $>50 \%$ of the total cost of valve replacement surgery; hence, any price regulation of valve price is likely to bring down the overall cost of treatment. The price of valves can be lowered by a range of measures-firstly, the capping of prices as in the case of cardiac stents [45]. Recently, the National Pharmaceutical Pricing Authority placed an upper limit on the price of cardiac stents, which lowered the price by $80 \%$. A similar regulatory action can be taken in the case of cardiac valves, as the price of the valve constitutes $50-57 \%$ (for mechanical and bio-prosthetic valves, respectively) of the total cost of replacement surgery [45]. Secondly, centralized procurement of drugs through the creation of medical service corporations at State level has been able to lower the drug prices significantly [46]. Including the procurement of cardiac valves through such agencies can further help in lowering the prices through competitive pricing. Thirdly, the launch 
Table 5 Out-of-pocket expenditure for mechanical and bio-prosthetic valve replacement surgeries in a tertiary care hospital

\begin{tabular}{|c|c|c|c|c|c|c|}
\hline \multirow[t]{3}{*}{ Costing variables } & \multicolumn{6}{|c|}{ Out-of-pocket expenditure in INR } \\
\hline & \multicolumn{2}{|l|}{ Mechanical valve } & \multicolumn{2}{|l|}{ Bio-prosthetic valve } & \multicolumn{2}{|c|}{ Balloon valvotomy } \\
\hline & Mean (SD) & Median (IQR) & Mean (SD) & Median (IQR) & Mean (SD) & Median (IQR) \\
\hline Cost of valve/balloon & $76,673(4039.4)$ & $55,000(50,000)$ & $91,667(29,633)$ & $76,000(99,000)$ & & \\
\hline Medicines & $34,767(2412.6)$ & $35,000(31,500)$ & $50,000(15,278)$ & $40,000(50,000)$ & $2672.2(1204)$ & $1425.45(985.9)$ \\
\hline Lab tests/diagnostics & $6095(636.7)$ & $5000(7000)$ & $9333(666.7)$ & $10,000(2000)$ & $737.4(182.4)$ & $380.1(380.1)$ \\
\hline $\begin{array}{l}\text { User fees/hospital } \\
\text { charges }^{\mathrm{a}}\end{array}$ & $5073(497.2)$ & $4000(7190)$ & $9603(5597.3)$ & $8000(19,190)$ & $18,787(828.4)$ & $17,400(567.8)$ \\
\hline Travelling & $4855(432.2)$ & $4000(6500)$ & $16,667(1666.6)$ & $15,000(5000)$ & $3278.5(332.6)$ & $2375.75(3207.2)$ \\
\hline Boarding/lodging/food & 4777 (357) & $4800(2650)$ & $4333(1764)$ & $5000(6000)$ & $2366(306)$ & $1900.6(1900.6)$ \\
\hline Informal payment & $121(103.5)$ & - & - & - & - & - \\
\hline Others & $775(260.6)$ & - & - & - & - & - \\
\hline Total expenditure & $133,136(5746.6)$ & $107,800(104,840)$ & $181,603(39,620)$ & $154,000(181,190)$ & $27,416(2749.2)$ & $23,481.913(7041.7)$ \\
\hline
\end{tabular}

$I N R$ Indian rupees, $I Q R$ interquartile range, $S D$ standard deviation

${ }^{a}$ User fees for balloon valvotomy are inclusive of cost of balloon and procedure charges (user fees and bed charges)

of AB-PMJAY - India's health insurance scheme-further offers the potential to reduce the cost of procedures through strategic purchasing and negotiation of prices with healthcare providers, given the large volumes. The costs for ECHO and ECG tests found in our study are much lower than the provider payment rates in social security schemes like the Central Government Health Scheme (CGHS), where per-unit ECHO, ECG, TMT and Holter tests cost INR1200-1400 (2D/3D), INR50, INR440 and INR850, respectively [47]. Hence, there is a need to leverage the existing central government policy system and revise the reimbursement packages under various health insurance schemes to optimize benefit for the beneficiaries, as well as make the provider payments appropriate.

The treatment of chronic diseases like valvular heart disease is exorbitant and can consume a significant portion of a household's income since the patients require treatment over a long duration and often need hospitalization [40]. Further, in countries like India, most of the healthcare finances are paid OOP by the households [35, 48]. As per the National Health Accounts Report 2014-2015, about $63 \%$ of health expenditure was financed by households from their pockets [35]. As per the national sample survey organization for the year 2014, average monthly OOP expenditure on hospitalization for the treatment of CVD was the second highest among all disease conditions reported in 2014 following cancer [28]. In addition to this, the share of NCDs (where CVDs dominate) in OOP health expenses increased from $31.6 \%$ in 1995-1996 to $47.3 \%$ in 2004 [49]. Moreover, the odds for catastrophic expenditure for CVDs are nearly $22 \%$ greater than the odds due to infectious diseases. Another Indian study on socioeconomic inequalities in the financing of diabetes and CVD reported that $30 \%$ of annual household expenditure was claimed for OOP payments for hospital treatment of CVD [50]. Further, to cope with such huge expenditure, households might have to undertake relatively risky coping strategies like borrowing or selling of assets to mobilize additional sums of money, leaving them vulnerable to impoverishment. Valvular heart diseases also negatively impact the economic well-being of households when the disease affects the productive and younger household members.

Therefore, there is a need to create some form of financial risk protection mechanism, either in the form of strengthening public health facilities by creating sufficient supply of infrastructure and human resource and raising the quality standards or by creating a prepayment mechanism in the form of social insurance to protect poor households from financial shocks. Secondly, our study estimates can be used for revision in the price of valves similar to the price capping of stents by the Government of India considering the high burden of OOP expenditure on patients. Thirdly, our study provides significant evidence on cost of cardiac care services, specifically focussing on heart valve disorders, and can help the government to bring down the overall cost of procedures by opting for new strategies of procurement such as bulk purchasing, knowing the extent to which drugs can be bargained. Fourthly, our study findings can help in regulating the demand side of cost sharing by private providers and will help to stop the practice of private providers charging the bill balance to patients despite having agreed to provide care based on a package. Finally, roll-out of the new national health insurance scheme AB-PMJAY is a step forward that has the potential to change the perception of the Indian healthcare landscape provided it is implemented in a methodical and systematic manner. This can only be achieved through appropriately designed package rates 
determined by robust costing studies like ours as well as through effective monitoring mechanisms during implementation along with thorough planning, proper utilization of resources, collaboration among stakeholders, synergy between the public and private players, transparency and accountability systems, etc.

\subsection{Strength of the Study}

As a whole, our study comprehensively estimates the cost of various cardiac care services using a micro-costing approach. Such micro-costing studies play an important role in providing clarity on unit cost estimates as usage of each input is estimated separately, and hence tends to be more comprehensive [22]. International agencies like Global Health Cost Consortium [51], National Institute for Health and Care Excellence in the United Kingdom, Health Intervention and Technology Assessment (HITAP) in Thailand have developed cost databases to inform policy and clinical decisions. Given the lack of such evidence on cost of healthcare services in India, there is a need to undertake more large-scale cost analysis studies to ultimately develop a cost database for all types of services. This could be useful for hospital managers, programme planners and researchers to undertake cost-effectiveness analysis.

\subsection{Limitations}

We would like to note a few limitations of our study. Firstly, we did not collect data on severity of disease at the time of admission and identify it as a limitation as this has some bearing on OOP expenditure. Secondly, our study estimates are based on data from a single tertiary care public sector hospital and have limited generalizability due to variation in study setting, consumption of resources, efficiency of different hospitals, etc. Thirdly, we did not assess indirect costs on account of lost productivity. However, the focus of our paper was to report the direct medical costs that are incurred by the health system and patient, such that it could be used to set provider payment rates under various government schemes. Fourthly, since the aggregate pooled data was available for resources at a tertiary care hospital, apportioning factors had to be applied to assess the cost at each cost centre. This could lead to some inaccuracy in the break-down of total costs obtained. Fifthly, since the procurement price data was not available for some equipment, we used market rates in such cases to represent the opportunity cost. Finally, administrative costs at institute level were not included. However, administrative costs at the departmental level were accounted for. Moreover, previous studies have shown that administrative costs account for $<0.5 \%$ of total costs in healthcare services provided in the public sector and were not found to have major effect [25]. Lastly, quality of services could clearly explain some of the variations in costs but it was beyond the scope of this study to estimate the quality of services being provided.

\section{Conclusion}

The present study provides information on overall cost of providing selected cardiac care services in tertiary care public sector hospitals in India. These results can be used for policy purposes, such as setting or revising the payment rates for provision of cardiac care including cost of valve replacement surgery and balloon valvotomy under various public-sector-financed insurance schemes and reimbursement packages. Moreover, our findings show that the current reimbursement rates set under India's Ayushman-Bharat Pradhan Mantri Jan Arogya Yojana (AB-PMJAY), despite widespread criticism by private hospitals, appear reasonable. Secondly, these cost estimates can also be used for administrative purposes like planning and management of cardiac care services or to improve the efficiency of hospitals. Finally, cost of cardiac care, as found in our study, would be useful for undertaking research to assess the cost effectiveness of various models of cardiac care.

Author Contributions Conceived the study: SP and RK. Study design: SP, RK, JD, YPS and SK. Study tools: SP and JD. Data collection: SP and JD. Data analysis: SP and JD. Validation of estimates: SP, RK, JD, YPS and SK. First draft: JD and SP. All authors reviewed and approved the final study draft.

Data Availability Statement Data on health system resources and patient-level data analysed during the current study are available from the corresponding author on reasonable request. The corresponding author can be contacted via email: shankarprinja@gmail.com.

\section{Compliance with Ethical Standards}

Funding The study was funded by the Indian Medical Council of Research (ICMR) under an extra-mural research grant.

Ethical approval The study was approved by the Institute Ethics Committee of the Postgraduate Institute of Medical Education and Research, Chandigarh, India.

Informed consent Informed consent was obtained from all individual participants in the study.

Conflict of interest All authors (Dr Shankar Prinja, Prof. Yashpaul Sharma, Dr Jyoti Dixit, Prof. Shyam Kumar Singh Thingnam and Prof. Rajesh Kumar) declare no conflict of interest. 
Open Access This article is distributed under the terms of the Creative Commons Attribution-NonCommercial 4.0 International License (http://creativecommons.org/licenses/by-nc/4.0/), which permits any noncommercial use, distribution, and reproduction in any medium, provided you give appropriate credit to the original author(s) and the source, provide a link to the Creative Commons license, and indicate if changes were made.

\section{References}

1. World Health Organization. Cardiovascular Disease: Global Atlas on Cardiovascular Disease Prevention and Control. Geneva: WHO, 2012. https://www.who.int/cardiovascular_diseases/publi cations/atlas_cvd/en/. Accessed 11 Feb 2018.

2. Smith SC Jr, Collins A, Ferrari R. Our time: a call to save preventable death from cardiovascular disease (heart disease and stroke). J Am Coll Cardiol. 2012;60:2343-8.

3. World Heart Federation. Urbanization and Cardiovascular Disease: Raising Heart-Healthy Children in Today's Cities. Geneva, Switzerland: World Health Federation; 2012. https://www.world -heart-federation.org/wp-content/uploads/2017/05/FinalWHFUr banizationLoResWeb.pdf. Accessed 11 Feb 2018.

4. World Economic Forum, The Global Economic Burden of Noncommunicable Diseases, Harvard School of Public Health; 2011. http://www3.weforum.org/docs/WEF_Harvard_HE_GlobalEcon omicBurdenNonCommunicableDiseases_2011.pdf. Accessed 16 Feb 2018.

5. GHSi. Shifting paradigm: how the BRICS are reshaping global health and development; 2012. http://www.ghsinitiatives.org/brics -report. Accessed Nov 2012.

6. World Health Organization and World Economic Forum. From Burden to "Best Buys": Reducing the Economic Impact of NCDs in Low and Middle-Income Countries. Geneva: WHO; 2011. https://www.who.int/nmh/publications/best_buys_summary.pdf. Accessed 16 Feb 2018.

7. Coffey S, Cairns BJ, Iung B. The modern epidemiology of heart valve disease. Heart. 2016;102:75-85.

8. Nkomo VT, Gardin JM, Skelton TN, et al. Burden of valvular heart diseases: a population-based study. Lancet. 2006;368:1005-11.

9. Yacoub MH, Takkenberg JJ. Will heart valve tissue engineering change the world? Nat Clin Pract Cardiovasc Med. 2005;2:60-1.

10. Press Information Bureau, Govt of India [homepage]: Special Service and Features; Rashtriya Bal Swasthya Karyakram (RBSK). http://pib.nic.in/newsite/efeatures.aspx?relid=94602. Updated 07/01/2015; cited 08 Jan 2015.

11. Pradhan Mantri Swasthya Surakha Yojana (PMSSY), MOHFW Government of India. http://www.mohfw.nic.in/index 4.php?lang $=1$ andlevel $=0$ andlinkid $=96$ andlid $=852$. Last cited 15 Sept 2012.

12. Directorate General of Health Services. 2010. National programme for prevention and control of cancer, diabetes, cardiovascular diseases, and stroke (NPCDCS): Operational guidelines. New Delhi: Ministry of Health and Family Welfare, Government of India. https://mohfw.gov.in/about-us/departments/department s-health-and-family-welfare/national-programme-prevention-andcontrol-cancer-diabetes-cardiovascular-disease-and. Accessed 11 Nov 2018.

13. Rashtriya Swasthya Bima Yojana website; 2012. https://www. india.gov.in/spotlight/rashtriya-swasthya-bima-yojana. Accessed 16 Aug 2018.

14. NHPS package rates too low: IMA [Internet]. The Economic Times; 2018. https://economictimes.indiatimes.com/industry/ healthcare/biotech/healthcare/nhps-package-rates-too-low-ima/ articleshow/64626317.cms. Cited 17 Sept 2018. Accessed 17 Dec 2018.

15. Karan A, Engelgau M, Mahal A. The household-level economic burden of heart disease in India. Trop Med Int Health. 2014;19(5):581-91.

16. Pankaj SN, Kanchan M. Economic effect of coronary heart disease on households - a study in Mumbai. Int J Med Public Health. 2016;6(4):184-8.

17. Chauhan S, Mukherjee K. Economic burden of coronary heart disease in North India. Int J Non Commun Dis. 2016;1:18-25.

18. Huffman MD, Rao KD, Pichon-Riviere A, Zhao D, Harikrishnan $\mathrm{S}$, Ramaiya $\mathrm{K}$, et al. A cross-sectional study of the microeconomic impact of cardiovascular disease hospitalization in four low- and middle-income countries. PLoS ONE. 2011;6:e20821.

19. Chatterjee $S$, Laxminarayan R. Costs of surgical procedures in Indian hospitals. BMJ Open. 2013;3(6):e002844.

20. Chatterjee S, Levin C, Laxminarayan R. Unit cost of medical services at different hospitals in India. PLoS ONE. 2013;8(7):e69728.

21. 47th Annual Report. Post-Graduation Institute of Medical Education and Research, Chandigarh; 2013-2014. http://pgimer.edu. in/PGIMER_PORTAL/PGIMERPORTAL/GlobalPages/JSP/ Page_Data.jsp?dep_id=89. Accessed 18 Aug 2018.

22. Drummond MF, Sculpher MJ, Torrance GW, O'Brien BJ, Stoddart GL. Methods for the economic evaluation of health care programmes. Oxford: Oxford University Press; 2005.

23. Janowitz B, Bratt JH. Methods for costing family planning services. New York: United Nations Population Fund and Family Health International; 1994.

24. Prinja S, Mazumder S, Taneja S, et al. Cost of delivering child health care through community level health workers: how much extra does IMNCI program cost? J Trop Pediatr. 2013;59:489-95.

25. Prinja S, Manchanda N, Mohan P, et al. Cost of neonatal intensive care delivered through district level public hospitals in India. Indian Pediatr. 2013;50:839-46. https://doi.org/10.1007/s1331 2-013-0234-6.

26. Sangwan A, Prinja S, Aggarwal S, Jagnoor J, Bahuguna P, Ivers R. Cost of trauma care in secondary- and tertiary-care public sector hospitals in North India. Appl Health Econ Health Policy. 2017; 15(5):681-92.

27. Prinja S, Gupta A, Verma R, Bahuguna P, Kumar D, Kaur M, et al. Cost of delivering health care services in public sector primary and community health centres in North India. PLoS ONE. 2016;11(8):e0160986.

28. National Sample Survey Office. Key Indicators of Social Consumption in India Health. New Delhi: Ministry of Statistics and Programme Implementation; 2015. http://mail.mospi.gov.in/index .php/catalog/161/download/1949. Accessed 2 Jan 2019.

29. Prinja S, Jagnoor J, Chauhan AS, Aggarwal S, Nguyen H, Ivers R. Economic burden of hospitalization due to injuries in North India: a cohort study. Int J Environ Res Public Health. 2016;13(7):673.

30. Wilkinson T, Sculpher MJ, Claxton K, et al. The international decision support initiative reference case for economic evaluation: an aid to thought. Value Health. 2016;19:921-8.

31. Edejer TT-T, Baltussen R, Adam T, Hutubessy R, Acharya A, et al. Making choices in health: WHO guide to cost-effectiveness analysis. Geneva: World Health Organization; 2003.

32. Economic Times. Forex Rates 2015. http://economictimes.india times.com/markets/forex. Accessed 12 Sept 2016.

33. Riewpaiboon A, Chatterjee S, Piyauthakit P. Cost analysis for efficient management: diabetes treatment at a public district hospital in Thailand. Int J Pharm Pract. 2011;19:342-9.

34. Ministry of Health, Gambia/World Health Organization. Cost analysis of the health care sector in the Gambia. Geneva: World Health Organization; 1995. 
35. Ministry of Health and Family Welfare, Government of India. National Health Accounts, India; 2004-2005. http://www.plann ingcommission.nic.in/reports/genrep/health/National_Health_ Account_04_05.pdf. Accessed 05 Jan 2016.

36. Bang A, Chatterjee M, Dasgupta J, Garg A, Jain Y, et al. High level expert group report on universal health coverage for India. New Delhi: Planning Commission of India; 2011.

37. Government of India. Report of the working group on tertiary care institutions for 12th five year plan (2012-17). Planning Commission. http://planningcommission.nic.in/aboutus/committee/wrkgr p12/health/WG_2tertiary.pdf. Accessed 24 Oct 2018.

38. Kruk ME, Wladis A, Mbembati N, Ndao-Brumblay SK, Hsia RY, et al. Human resource and funding constraints for essential surgery in district hospitals in Africa: a retrospective cross-sectional survey. PLos Med. 2010;7:e1000242.

39. High Level Expert Group Report on Universal Health Coverage for India. Planning Commission of India; New Delhi, 2011. http:// planningcommission.nic.in/reports/genrep/rep_uhc0812.pdf. Accessed 19 Nov 2018.

40. Selvaraj S, Karan AK. Why publicly-financed health insurance schemes are ineffective in providing financial risk protection. Econ Polit Wkly. 2012;XIVII:11.

41. Government's New Health Insurance Scheme Should Be Based on Evidence, Transparency [Internet]. The Wire; 2018. https://thewi re.in/health/governments-new-health-insurance-scheme-shoul d-be-based-on-evidence-transparency. Cited 17 Sept 2018.

42. Arogyasri Scheme. http://aarogyasri.telangana.gov.in/web/guest/ aarogyasri-scheme. Cited 20 Apr 2017.

43. Mahatma Jyotiba Phule Jan Arogya Yojana in Maharashtra. https ://www.jeevandayee.gov.in/. Accessed 20 Apr 2017.
44. Chief Minister's Comprehensive Health Insurance Scheme. http:// www.cmchistn.com/. Cited 21 Apr 2017.

45. Published in Part II, Section 3, Sub Section (ii) of the Gazette of India Extraordinary, 13th February 2017. Government of India, Ministry of Chemicals and Fertilizers, Department of Pharmaceuticals, National Pharmaceuticals Pricing Authority, New Delhi. http://www.nppaindia.nic.in/ceiling/press28July17/01so270420 17e2-28-07-17_5.pdf. Accessed 26 Nov 2018.

46. Chokshi M, Farooqui HH, Selvaraj S, Kumar P. A cross-sectional survey of the models in Bihar and Tamil Nadu, India for pooled procurement of medicines. WHO South East Asia J Public Health. 2015;4(1):78-85.

47. Government of India, Ministry of Health and Family Welfare, Central Government Health Scheme [Internet]. http://cghs.nic.in/. Cited 24 Oct 2016.

48. Mahal A, Karan A, Engelgau M. The Economic Implications of Non-Communicable Disease for India, HNP Discussion Paper. Washington, DC: World Bank; 2010. http://siteresources.world bank.org/HEALTHNUTRITIONANDPOPULATION/Resou rces/281627-1095698140167/EconomicImplicationsofNCDforIn dia.pdf. Accessed 27 Dec 2018.

49. Engelgau MM, Karan A, Mahal A. The economic impact of noncommunicable diseases on households in India. Glob Health. 2012;8:9.

50. Rao KD, Bhatnagar A, Murphy A. Socio-economic inequalities in the financing of cardiovascular and diabetes inpatient treatment in India. Indian J Med Res. 2011;133:57-63.

51. GHCC I Global Heath Cost Consortium [Internet]. https://ghcos ting.org/pages/standards/introduction/estimating_the_cost_of_ health_interventions_an_introduction. Cited 20 Apr 2018. 